\title{
STABILISASI TANAH LEMPUNG MENGGUNAKAN SOIL BINDER
}

\author{
Asriwiyanti Desiani, Salijan Redjasentana \\ Jurusan Teknik Sipil Fakultas Teknik Universitas Kristen Maranatha \\ Email: asriwiyanti@gmail.com
}

\begin{abstract}
ABSTRAK
Berbagai teknik perbaikan tanah dapat dilakukan untuk memperbaiki masalah yang terjadi pada saat membangun di atas tanah lempung lunak. Memperbaiki tanah yang ada dengan menggunakan bahan tambahan disebut stabilisasi tanah. Proses tersebut dapat mengurangi penurunan, meningkatkan kuat geser tanah yang berarti meningkatkan daya dukung pondasi, meningkatkan faktor keamanan lereng timbunan, maupun menurunkan karakteristik penyusutan dan pemuaian tanah (Das, 2007) Berbagai cara digunakan untuk memperbaiki kekuatan dari tanah lempung diantaranya dengan penambahan bahan kimia (stabilisasi secara kimiawi). Penelitian ini bertujuan untuk mengkaji pengaruh bahan tambahan soil binder Vienison SB terhadap kekuatan tanah dasar yang dinyatakan dalam nilai CBR (California Bearing Ratio). Sampel tanah lempung diambil dari daerah Cicalengka Kabupaten Bandung, sedangkan bahan soil binder yang digunakan konsentrasinya divariasikan sebesar 150 gram $/$ liter air $/ \mathrm{m}^{2}$ tanah, 200 gram $/$ liter air $/ \mathrm{m}^{2}$ tanah dan 300 gram $/$ liter air $/ \mathrm{m}^{2}$ tanah. Hasil menunjukkan tanah lempung yang digunakan memiliki Gs 2.68 dan berdasar klasifikasi USCS tergolong sebagai Sandy fat clay dengan group symbol $\mathrm{CH}$. Pengujian pemadatan pada tanah asli menghasilkan nilai kepadatan kering maksimum $\gamma_{\mathrm{d}}=1.6 \mathrm{gr} / \mathrm{cm}^{3}$ dan kadar air optimum $22 \%$. Nilai CBR desain pada $95 \%$ kepadatan kering maksimum $6.9 \%$. Nilai ini menunjukkan tanah buruk untuk dijadikan tanah dasar. Akibat penambahan soil binder terjadi peningkatan $\gamma_{\mathrm{d}}$ antara 2-14\% dan peningkatan nilai CBR antara 41-276\%. Penambahan Soil Binder sebesar 150 sampai 300 gram $/$ liter air $/ \mathrm{m}^{2}$ tanah dapat meningkatkan nilai CBR desain sebesar 13 sampai $76 \%$. Hasil penelitian menunjukkan penambahan soil binder Vienison SB dapat meningkatkan nilai CBR pada tanah cukup signifikan.
\end{abstract}

Kata kunci : Tanah lempung, stabilisasi, soil binder.

\section{PENDAHULUAN}

Di Indonesia, daerah terbesar tanah lempung lunak terletak di sepanjang pesisir pantai utara Sumatera sampai Sumatera Selatan, sepanjang pesisir pantai utara Jawa, Kalimantan Selatan dan Papua Selatan (Cox, 1970). Membangun di atas lempung lunak menyebabkan banyak masalah, terutama masalah penurunan yang besar dan daya dukung rendah.

Berbagai teknik perbaikan tanah dapat dilakukan untuk memperbaiki masalahmasalah tersebut di atas. Memperbaiki tanah yang ada dengan menggunakan bahan tambahan disebut stabilisasi tanah. Proses tersebut dapat mengurangi penurunan, meningkatkan kuat geser tanah yang berarti meningkatkan daya dukung pondasi, meningkatkan faktor keamanan lereng timbunan, maupun menurunkan karakteristik Stabilisasi Tanah Lempung Menggunakan Soil Binder 
penyusutan dan pemuaian tanah (Das, 2007) .Bahan tambahan yang umum digunakan adalah kapur, kapur-abu terbang(fly-ash), semen dan aspal serta berbagai bahan kimia.

Saat ini telah dikembangkan stabilisasi tanah dengan bahan kimia berbahan dasar lateks yang ramah lingkungan. Bahan tersebut umum disebut sebagai Soil Binder (Pengikat tanah), yang bila diaplikasikan akan membentuk permukaan tanah sekeras semen. Penelitian ini bertujuan untuk mengkaji pengaruh bahan tambahan soil binder Vienison SB terhadap kekuatan tanah dasar yang dinyatakan dalam nilai CBR (California Bearing Ratio).

\section{TINJAUAN PUSTAKA}

Tanah lempung merupakan partikel mineral yang berukuran lebih kecil dari 0,002 mm. Partikel-partikel ini merupakan sumber utama dari kohesi di dalam tanah yang kohesif (Bowles, 1991). Tanah lempung merupakan tanah yang berukuran mikroskopis sampai dengan sub mikroskopis yang berasal dari pelapukan unsur-unsur kimiawi penyusun batuan, tanah lempung sangat keras dalam keadaan kering dan bersifat plastis pada kadar air sedang. Pada kadar air lebih tinggi, lempung bersifat lengket (kohesif) dan sangat lunak (Das, 1988).

ASTM memberi batasan bahwa secara fisik ukuran lempung adalah lolos saringan No.200. Untuk menentukan jenis lempung tidak cukup hanya dilihat dari ukuran butirannya saja tetapi perlu diketahui mineral pembentuknya. Menurut Chen (1975), mineral lempung terdiri dari tiga komponen penting yaitu montmorillonite, illite dan kaolinite. Mineral montmorilonite mempunyai luas permukaan lebih besar dan sangat mudah menyerap air dalam jumlah banyak bila dibandingkan dengan mineral lainnya, sehingga tanah yang mempunyai kepekaan terhadap pengaruh air ini sangat mudah mengembang. Karena sifat-sifat tersebut montmorilonite sangat sering menimbulkan masalah pada bangunan.

Salah satu upaya untuk mendapatkan sifat tanah yang memenuhi syaratsyarat teknis tertentu adalah dengan metode stabilisasi tanah. Metode stabilisasi tanah dapat dibagi menjadi 3 jenis yaitu stabilisasi mekanis, stabilisasi fisik, dan stabilisasi kimiawi (Ingles dan Metcalf, 1972). Saat ini dikembangkan stabilisasi tanah dengan bahan kimia berbahan dasar lateks yang ramah lingkungan. Bahan tersebut umum disebut sebagai Soil Binder (Pengikat tanah), yang bila diaplikasikan akan membentuk permukaan tanah sekeras semen.

Soil Binder mudah digunakan serta berbiaya rendah, umum dipakai untuk perawatan tetap pada jalan setapak, jalan kendaraan, jalan raya, area parkir dan area 
penyimpanan /pergudangan, bendung, dan saluran air. Kemudahan aplikasi disebabkan alat yang dipakai mudah ditemukan dilapangan seperti Road Grader, Water Tanker with Spray bar dan Drum compactor.

Keuntungan penggunaan Soil Binder (Pengikat tanah) antara lain menahan erosi tanah, mengurangi pekerjaan pemeliharaan, lapis permukaan yang keras, pelindung debu, meningkatkan keamanan publik, mengurangi pengaruh buruk lingkungan. Penggunaan yang dikombinasikan dengan pemadatan akan meningkatkan kepadatan tanah dan mengurangi permeabilitas.

Keenceran (Dilution) dari Soil binder akan mempengaruhi luas daerah yang akan distabilisasi. Semakin encer soil binder maka daerah yang dapat distabilisasi semakin luas. Gambar 2.1. menunjukkan, panjang jalan, lebar jalan, kedalaman dan luas tanah yang dapat distabilisasi berdasar keenceran soil binder.

\begin{tabular}{|c|c|c|c|c|c|}
\hline \multicolumn{6}{|c|}{$\begin{array}{l}\text { Chart giving approximation of Soil Binder usage varying } \\
\text { The dilution ratio and scarification depth }\end{array}$} \\
\hline $\begin{array}{l}\text { Soil Binder } \\
\text { one Container }\end{array}$ & $\begin{array}{l}\text { Product Dilution } \\
\text { Ratio }\end{array}$ & $\begin{array}{l}\text { Scarification } \\
\text { Depth }\end{array}$ & Road Length & Road Width & Coverage $\left(\mathrm{m}^{2}\right)$ \\
\hline $15,000 \mathrm{~L}$ & $1: 7$ & $15 \mathrm{~cm}$ & $3.70 \mathrm{~km}$ & $9 \mathrm{~m}$ & $33,333 \mathrm{~m}^{2}$ \\
\hline $15,000 \mathrm{~L}$ & 1:9 & $15 \mathrm{~cm}$ & $4.76 \mathrm{~km}$ & $9 \mathrm{~m}$ & $42,857 \mathrm{~m}^{2}$ \\
\hline $15,000 \mathrm{~L}$ & $1: 7$ & $12.5 \mathrm{~cm}$ & $4.44 \mathrm{~km}$ & $9 m$ & $40,000 \mathrm{~m}^{2}$ \\
\hline $15,000 \mathrm{~L}$ & $1: 9$ & $12.5 \mathrm{~cm}$ & $5.71 \mathrm{~km}$ & $9 \mathrm{~m}$ & $51,428 \mathrm{~m}^{2}$ \\
\hline $15,000 \mathrm{~L}$ & $1: 7$ & $10 \mathrm{~cm}$ & $5.56 \mathrm{~km}$ & $9 \mathrm{~m}$ & $50,000 \mathrm{~m}^{2}$ \\
\hline $15,000 \mathrm{~L}$ & $1: 9$ & $10 \mathrm{~cm}$ & $7.14 \mathrm{~km}$ & $9 \mathrm{~m}$ & $64,285 \mathrm{~m}^{2}$ \\
\hline $\begin{array}{l}\text { Note: These } \\
\text { the amount o }\end{array}$ & $\begin{array}{l}\text { nsions have } \\
\text { es present in }\end{array}$ & $\begin{array}{l}\text { ying facto } \\
\text { soil, } 17 \%\end{array}$ & $\begin{array}{l}\text { ich is dep } \\
\text { the minit }\end{array}$ & $\begin{array}{l}\text { ant on the } \\
\text { i needed. }\end{array}$ & pe of soil and \\
\hline
\end{tabular}

Gambar 2.1 Perkiraan keenceran soil binder terhadap luasan stabilisasi.

\section{Sumber: www.ofbcorporation.com}




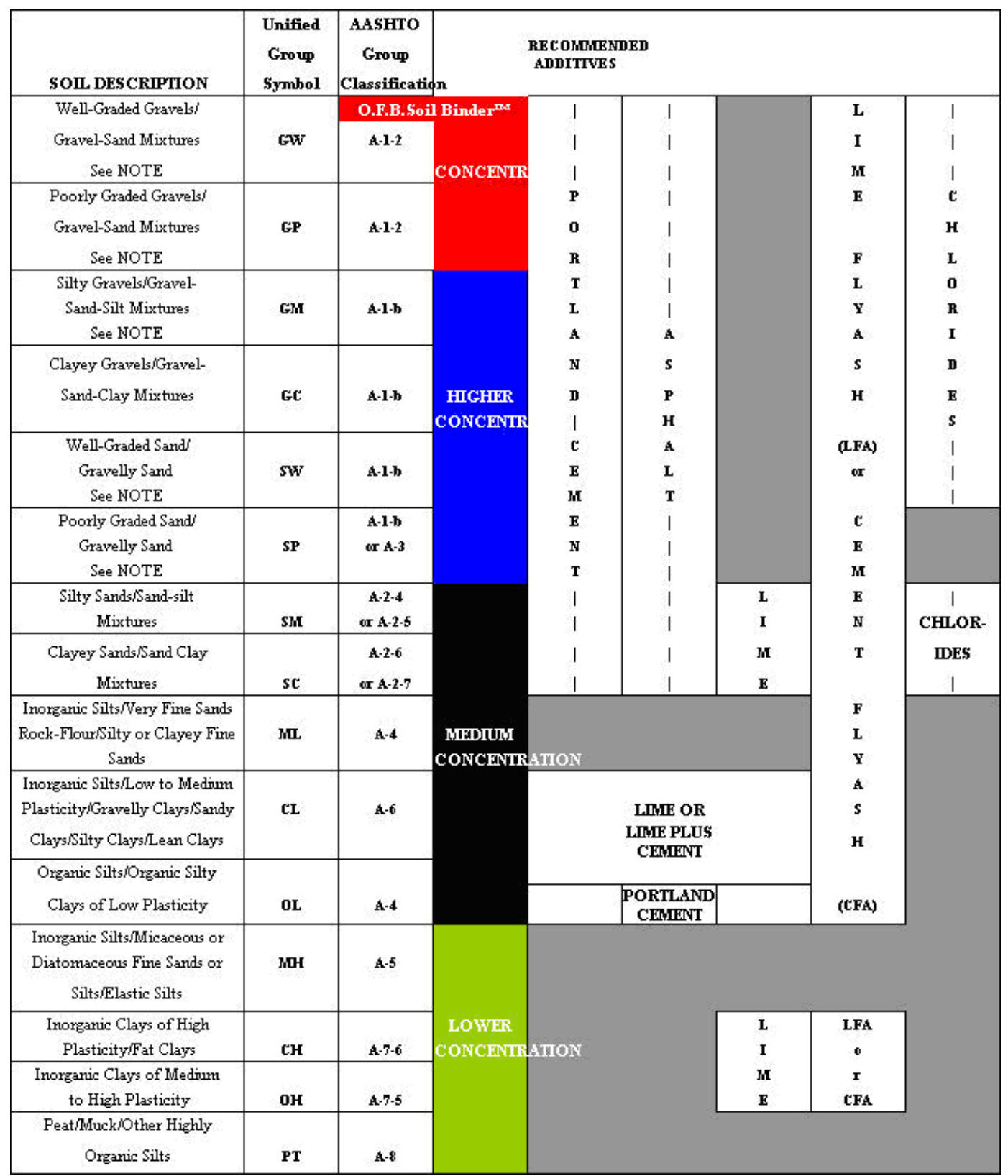

\section{Gambar 2.2 Kondisi konsentrasi soil binder terhadap jenis tanah}

Sumber: www.ofbcorporation.com

Jenis tanah yang dapat distabilisasi menggunakan soil binder sangat bervariasi. Soil binder dapat diaplikasikan pada tanah butir kasar dan tanah butir halus dengan kadar konsentrasi bergantung pada jenis tanahnya. Gambar 2.2 memperlihatkan jenis tanah berdasar klasifikasi USCS dan AASHTO dan kadar konsentrasi soil binder merk O.F.B. yang dapat digunakan untuk menstabilisasi tanah-tanah tersebut.

Uji CBR merupakan uji sederhana yang umum digunakan untuk menentukan indikasi kekuatan material tanah dasar, lapisan sub-base dan lapisan base dari jalan atau 
perkerasan Bandar udara Hasil uji dapat digunakan untuk penentuan awal secara empiris ketebalan perkerasan fleksibel pada jalan dan Bandar udara. Nilai CBR untuk berbagai jenis tanah dapat dilihat pada Gambar 2.3 dan Gambar 2.4.

California Bearing Ratio (CBR) suatu tanah adalah perbandingan antara tegangan penetrasi suatu tanah terhadap tegangan penetrasi material standar dinyatakan dalam $\%$.

\begin{tabular}{|c|c|c|c|c|c|c|c|c|c|c|}
\hline \multirow{2}{*}{\multicolumn{2}{|c|}{ Majar ванав: }} & \multicolumn{3}{|c|}{ brated } & \multirow[b]{2}{*}{$\begin{array}{l}\text { Hean } \\
\text { (6) }\end{array}$} & \multirow{2}{*}{ 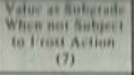 } & \multirow{2}{*}{ 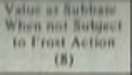 } & \multirow{2}{*}{ 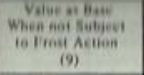 } & \multirow{2}{*}{ 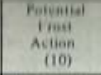 } & \multirow{2}{*}{ 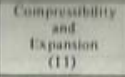 } \\
\hline & & \begin{tabular}{|c|c|} 
Lenteis \\
(3)
\end{tabular} & $\begin{array}{l}\text { Warthime } \\
\text { (4) }\end{array}$ & $\begin{array}{c}\text { Colar } \\
\text { (s) }\end{array}$ & & & & & & \\
\hline \multirow{10}{*}{$\begin{array}{l}\text { COARSE. } \\
\text { GRAINED } \\
\text { SOILS }\end{array}$} & \multirow{5}{*}{$\begin{array}{l}\text { GRAVEL } \\
\text { AND } \\
\text { GRAVRLLY } \\
\text { SOILS }\end{array}$} & GW & $\therefore$ & \multirow{2}{*}{ Red } & 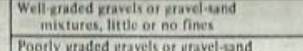 & Freetlent & Fiscellent & Good & \begin{tabular}{|c|} 
Nonen to very \\
slight
\end{tabular} & Alinost none \\
\hline & & GP & $\because$ & & $\begin{array}{l}\text { Pootly graded mavels of thavel-and } \\
\text { mixutures, litille or no fines }\end{array}$ & Good to exeellent & Good & Fait to pood & $\begin{array}{c}\text { None to very } \\
\text { dipht }\end{array}$ & Almost none \\
\hline & & id & int & \multirow{3}{*}{ Yellow } & \multirow{2}{*}{ Silty pravels, pravel-sand-silt mixtures } & Good to excellent & Good & Fair to kood & $\begin{array}{l}\text { Stight to } \\
\text { medium_ }\end{array}$ & Very slight \\
\hline & & : & 10 & & & Good & Fait & Poor to not suitable & $\begin{array}{c}\text { Slighh to } \\
\text { medium }\end{array}$ & Slight \\
\hline & & $\mathrm{GC}$ & & & Claycy pravels, yravel-sand-clay mixtures & Good & Vaitr & Poor to not suitsble & $\begin{array}{c}\begin{array}{c}\text { Slizht to } \\
\text { medium }\end{array} \\
\end{array}$ & Slipht \\
\hline & \multirow{5}{*}{$\begin{array}{l}\text { SAND } \\
\text { AND } \\
\text { SANDY } \\
\text { SOHLS }\end{array}$} & sw & & \multirow{2}{*}{ Red } & \begin{tabular}{|l} 
Well-graded sands or pravelly sinds, \\
liftle or no fins
\end{tabular} & Good & \begin{tabular}{|l|} 
Fair to good \\
\end{tabular} & Poot & $\begin{array}{c}\text { None to very } \\
\text { sight }\end{array}$ & Almost none \\
\hline & & SP & & & $\begin{array}{l}\text { Poorty graded sands or pravelly sands, } \\
\text { little or no fins }\end{array}$ & V'air to good & Fair & Poor to not saitable & $\begin{array}{c}\text { None to very } \\
\text { slikht }\end{array}$ & Almost none \\
\hline & & id & ititis & \multirow{3}{*}{ Yellow } & \multirow{2}{*}{ Silty sands, sand-sill mixtures } & Fait to pood & Vair to pood & Poor & $\begin{array}{l}\text { Shight to } \\
\text { hipht- }\end{array}$ & Very slight \\
\hline & & i" & $1+10$ & & & Fait & Poor to fair & Not suitable & $\begin{array}{c}\text { Slipht to } \\
\text { hitiph } \\
\end{array}$ & Slight to medium \\
\hline & & sc & & & Clayey snds, sand-clay mixtures & Poor to fair & Poor & Not suitable & $\begin{array}{c}\text { Sipeltit to } \\
\text { hiph }\end{array}$ & Slizht to medium \\
\hline \multirow{6}{*}{$\begin{array}{l}\text { IVNE, } \\
\text { GRAINED } \\
\text { SOILS }\end{array}$} & \multirow{3}{*}{$\begin{array}{l}\text { SILTS } \\
\text { AND } \\
\text { CLAYS } \\
\text { LLIS } \\
\text { LISS } \\
\text { THAN SO }\end{array}$} & ML & & \multirow{3}{*}{ Green } & 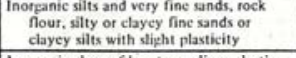 & Poor to fair & Not suitable & Not suitable & $\begin{array}{l}\text { Medium to } \\
\text { very high }\end{array}$ & Slipht to medium \\
\hline & & $\mathrm{Cl}$ & & & $\begin{array}{l}\text { Inorganic chays of low to medium plastic- } \\
\text { ity, froveclil clays, sandy clays, silty } \\
\text { days, kean clays }\end{array}$ & Poor to fait & Not suitable & Not suitable & $\begin{array}{l}\text { Medium to } \\
\text { hiph }\end{array}$ & Medium \\
\hline & & oL & Bis & & $\begin{array}{l}\text { Orfanic silts and oftanic silt-clays of } \\
\text { low plasticity }\end{array}$ & Poor & Not switable & Not suitable & $\begin{array}{c}\text { Modium to } \\
\text { hiph }\end{array}$ & Medium to high \\
\hline & \multirow{3}{*}{\begin{tabular}{|l} 
SILTS \\
AND \\
CLAYS \\
LLIS \\
GRIAATIR \\
THAN 50 \\
\end{tabular}} & МH & 10 & \multirow{3}{*}{ Blue } & 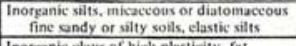 & Poor & Nor stitable & Not suitable & $\begin{array}{c}\text { Medium to } \\
\text { very high }\end{array}$ & Hizh \\
\hline & & $\mathrm{CH}$ & a & & $\begin{array}{l}\begin{array}{l}\text { Inorpanic clays of hizh plasticity, fat } \\
\text { clays }\end{array} \\
\end{array}$ & Poor to fair & Not suitable & Not suitable & Medium & Hifth \\
\hline & & oll & 絈 & & 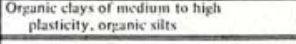 & Poor to very poot & Not suitable & Not suitable & Mcdium & Hich \\
\hline \multicolumn{2}{|c|}{$\begin{array}{l}\text { HIGHLY ORGANIC } \\
\text { SOILS }\end{array}$} & $P_{1}$ & 렸 & Oranke & Peat and othec hizhly ofpanic soils & Not suitable & Not suitable & Not suitable & Slith ht & Very hieh \\
\hline
\end{tabular}

Gambar 2.3 Perkiraan Nilai CBR untuk berbagai jenis tanah (Sumber: Kovacs).

\begin{tabular}{|c|c|c|c|c|c|c|c|c|c|c|}
\hline \multirow{3}{*}{\multicolumn{2}{|c|}{ Major Divisions }} & \multicolumn{3}{|c|}{ Symbol } & \multirow{4}{*}{$\begin{array}{c}\text { Drainage } \\
\text { Characteristics } \\
\text { (12) }\end{array}$} & \multirow{4}{*}{$\begin{array}{c}\text { Compaction Equipment } \\
\text { (13) }\end{array}$} & \multirow{2}{*}{\multicolumn{2}{|c|}{ Unit Dry Densities }} & \multicolumn{2}{|c|}{ Typical Design Values } \\
\hline & & \multirow{3}{*}{$\begin{array}{c}\text { Letter } \\
\text { (3) }\end{array}$} & \multirow{3}{*}{$\begin{array}{c}\text { Hatching } \\
\text { (4) }\end{array}$} & \multirow{3}{*}{$\begin{array}{c}\text { Color } \\
(5)\end{array}$} & & & & & \multirow{3}{*}{$\begin{array}{l}\text { CBR } \\
(16) \\
\end{array}$} & \multirow{3}{*}{$\begin{array}{c}\text { Subgrade Modulus } \\
\left.\text { k (1bf/in. }{ }^{3}\right) \\
\text { (17) }\end{array}$} \\
\hline & & & & & & & $\mathrm{lb} / \mathrm{ft} \mathrm{t}^{3}$ & $\mathrm{Mg} / \mathrm{m}^{3}$ & & \\
\hline (1) & (2) & & & & & & (14) & (15) & & \\
\hline \multirow{10}{*}{$\begin{array}{l}\text { COARSE- } \\
\text { GRAINED } \\
\text { SOILS }\end{array}$} & \multirow{5}{*}{$\begin{array}{l}\text { GRAVEL } \\
\text { AND } \\
\text { GRAVELLY } \\
\text { SOILS }\end{array}$} & GW & $\because$ & \multirow{2}{*}{ Red } & Excellent & $\begin{array}{l}\text { Crawler-type tractor, rubber-tired } \\
\text { rollet, steel-wheeled roller }\end{array}$ & $125-140$ & $2.00-2.24$ & $40-80$ & $300-500$ \\
\hline & & GP & 8 & & Excellent & $\begin{array}{l}\text { Crawler-type tractor, rubber-tired } \\
\text { roller, steel-wheeled rollet }\end{array}$ & $110-140$ & $1.76-2.24$ & $30-60$ & $300-500$ \\
\hline & & \multirow{2}{*}{\begin{tabular}{|l:c} 
& d \\
GM & u \\
&
\end{tabular}} & \multirow{3}{*}{ (4) } & \multirow{3}{*}{ Yellow } & Fair to poor & $\begin{array}{l}\text { Rubber-tired roller, sheepsfoot } \\
\text { roller; close control of moisture }\end{array}$ & $125-145$ & $2.00-2.32$ & $40-60$ & $300-500$ \\
\hline & & & & & $\begin{array}{c}\text { Poor to practically } \\
\text { impervious }\end{array}$ & $\begin{array}{l}\text { Rubber-tired roller, sheepsfoot } \\
\text { rollet }\end{array}$ & $115-135$ & $1.84-2.16$ & $20-30$ & $200-500$ \\
\hline & & GC & & & \begin{tabular}{|c|}
$\begin{array}{c}\text { Poor to practically } \\
\text { impervious }\end{array}$ \\
\end{tabular} & $\begin{array}{l}\text { Rubber-tired roller, sheepsfoot } \\
\text { foller }\end{array}$ & $130-145$ & $2.08-2.32$ & $20-40$ & $200-500$ \\
\hline & \multirow{5}{*}{$\begin{array}{l}\text { SAND } \\
\text { AND } \\
\text { SANDY } \\
\text { SOILS }\end{array}$} & sw & & \multirow{2}{*}{ Red } & Excellent & $\begin{array}{l}\text { Crawler-type tractor, rubber-tired } \\
\text { roller }\end{array}$ & $110-130$ & $1.76-2.08$ & $20-40$ & $200-400$ \\
\hline & & SP & & & Excellent & $\begin{array}{l}\text { Crawler-type tractor, rubber-tired } \\
\text { roller }\end{array}$ & $105-135$ & $1.68-2.16$ & $10-40$ & $150-400$ \\
\hline & & \multirow{3}{*}{\begin{tabular}{|c|c|} 
id \\
SML- \\
Iu \\
SC \\
\end{tabular}} & \multirow{3}{*}{ in: } & \multirow{3}{*}{ Yellow } & Fair to poor & $\begin{array}{l}\text { Rubber-tired roller, sheepsfoot } \\
\text { roller, close control of moisture }\end{array}$ & $120-135$ & $1.92-2.16$ & $15-40$ & $150-400$ \\
\hline & & & & & $\begin{array}{c}\text { Poor to practically } \\
\text { impervious }\end{array}$ & $\begin{array}{l}\text { Rubber-tired toller, sheepsfoot } \\
\text { roller }\end{array}$ & $100-130$ & $1.60-2.08$ & $10-20$ & $100-300$ \\
\hline & & & & & $\begin{array}{c}\begin{array}{c}\text { Poor to practically } \\
\text { impervious }\end{array} \\
\end{array}$ & $\begin{array}{l}\text { Rubber-fired roller, sheepsfoot } \\
\text { roller }\end{array}$ & $100-135$ & $1.60-2.16$ & $5 \cdot 20$ & $100-300$ \\
\hline \multirow{6}{*}{$\begin{array}{l}\text { FINE. } \\
\text { GRAINED } \\
\text { SOILS }\end{array}$} & \multirow{3}{*}{$\begin{array}{c}\text { SILTS } \\
\text { AND } \\
\text { CLAYS } \\
\text { LLIS } \\
\text { LESS } \\
\text { THAN } 50 \\
\end{array}$} & ML & ||| | & \multirow{3}{*}{ Green } & Fair to poor & \begin{tabular}{|l|} 
Rubber-tired roller, sheepsfoot \\
roller; close control of moisture
\end{tabular} & $90-130$ & $1.44-2.08$ & $\begin{array}{l}15 \text { or } \\
\text { less }\end{array}$ & $100-200$ \\
\hline & & $\mathrm{CL}$ & Ba & & \begin{tabular}{|c|}
$\begin{array}{c}\text { Practically } \\
\text { impervious }\end{array}$ \\
\end{tabular} & $\begin{array}{l}\text { Rubber-tired roller, sheepsfoot } \\
\text { roller }\end{array}$ & $90-130$ & $1.44-2.08$ & \begin{tabular}{|l|}
15 or \\
less
\end{tabular} & 50.150 \\
\hline & & OL & Sostits & & Poor & $\begin{array}{l}\text { Rubber-tired roller, sheepsfoot } \\
\text { roller }\end{array}$ & $90-105$ & $1.44-1.68$ & \begin{tabular}{|l|}
$\begin{array}{l}5 \\
\text { or } \\
\text { less }\end{array}$ \\
\end{tabular} & $50-100$ \\
\hline & \multirow{3}{*}{$\begin{array}{c}\text { SILTS } \\
\text { AND } \\
\text { CLAYS } \\
\text { LL IS } \\
\text { GREATER } \\
\text { THAN S0 } \\
\end{array}$} & MH & & \multirow{3}{*}{ Blue } & Fair to poor & $\begin{array}{l}\begin{array}{l}\text { Sheepsfoot roller, rubber-tired } \\
\text { toller }\end{array} \\
\end{array}$ & $80-105$ & $1.28-1.68$ & $\begin{array}{l}10 \text { or } \\
\text { less } \\
\end{array}$ & $50-100$ \\
\hline & & $\mathrm{CH}$ & 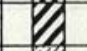 & & $\begin{array}{c}\begin{array}{c}\text { Practically } \\
\text { impervious }\end{array} \\
\end{array}$ & $\begin{array}{l}\text { Sheepsfoot roller, rubber-tired } \\
\text { roller }\end{array}$ & $90-115$ & $1.44-1.84$ & \begin{tabular}{|l|}
15 or \\
less
\end{tabular} & $50-150$ \\
\hline & & $\mathrm{OH}$ & 聄 & & $\begin{array}{l}\begin{array}{l}\text { Practically } \\
\text { impervious }\end{array} \\
\end{array}$ & $\begin{array}{l}\text { Sheepsfoot roller, rubber-tired } \\
\text { roller }\end{array}$ & $80-110$ & $1.28-1.76$ & $\begin{array}{l}5 \text { or } \\
\text { less }\end{array}$ & $25 \cdot 100$ \\
\hline \multicolumn{2}{|c|}{$\begin{array}{l}\text { HIGHLY ORGANIC } \\
\text { SOILS }\end{array}$} & $\mathrm{Pt}$ & & Orange & Fair to poor & Compaction not practical & & & & \\
\hline
\end{tabular}

Gambar 2.4. Perkiraan Nilai CBR untuk berbagai jenis tanah (2) (Sumber: Kovacs).

\section{METODA PENELITIAN}




\subsection{Persiapan Benda Uji}

Tanah lempung yang digunakan adalah tanah lempung dari daerah Cicalengka Kabupaten Bandung. Contoh tanah diambil dalam keadaan terganggu dengan menggunakan sekop dan cangkul lalu dimasukkan ke dalam karung. Contoh tanah diambil pada kedalaman $50 \mathrm{~cm}$.

Bahan kimia yang digunakan adalah tipe soil binder dengan merk Vienison SB. Penambahan soil binder dalam penelitian divariasikan konsentrasinya sebesar 150 gram $/$ liter air $/ \mathrm{m}^{2}$ tanah, 200 gram $/$ liter air $/ \mathrm{m}^{2}$ tanah dan 300 gram $/$ liter air $/ \mathrm{m}^{2}$ tanah.

\subsection{Prosedur Pengujian}

Pengujian indeks properti tanah, konsistensi atterberg, analisis saringan, pemadatan (Standard Proctor) dan CBR mengacu pada standar ASTM seperti tercantum pada Tabel 3.1. Pengujian dilakukan di Laboratorium Mekanika Tanah Universitas Kristen Maranatha Bandung.

Tabel 3.1. Standard ASTM yang digunakan.

\begin{tabular}{|l|l|l|}
\hline No. & Pengujian & ASTM No. \\
\hline A & Indeks properties & \\
\hline 1 & Specific Gravity (Gs) & D-854 \\
\hline 2 & Kadar Air natural (w) & D-2216 \\
\hline B & Konsistensi Atterberg & \\
\hline 1 & Batas Cair (LL) & D-4318 \\
\hline 2 & Batas Plastis (PL) & D-4318 \\
\hline C & Analisis Saringan & D-422 \\
\hline D & Sifat mekanis & \\
\hline 1 & $\begin{array}{l}\text { Pemadatan lab. } \\
\text { (Standard Proctor) }\end{array}$ & D-698 \\
\hline 2 & Daya dukung CBR & D-1883 \\
\hline
\end{tabular}

Proses diawali pencampuran soil binder dengan air sesuai konsentrasi yang direncanakan, kemudian dilakukan pengadukan tanah lempung terganggu dengan soil binder sampai campuran terlihat homogen. Kandungan kadar air tanah lempung pada saat pengadukan adalah kondisi kadar air optimum. Hasil pencampuran ditutup rapat dengan plastik dan didiamkan selama \pm 2 jam untuk memberikan kesempatan soil binder meresap pada benda uji namun pengerasan belum terjadi maksimal. Campuran tanah dimasukkan ke dalam cetakan kompaksi dan ditumbuk tiga lapis dimana jumlah tumbukan perlapis 
berbeda-beda, 10, 25, dan 56 tumbukan perlapis. Masing-masing sampel di uji pada alat CBR dan dicari nilai kepadatan keringnya. Gambar 3.1, Gambar 3.2, dan Gambar 3.3 memperlihatkan pencampuran tanah dan soil binder, pemadatan dan pengujian CBR di laboratorium.

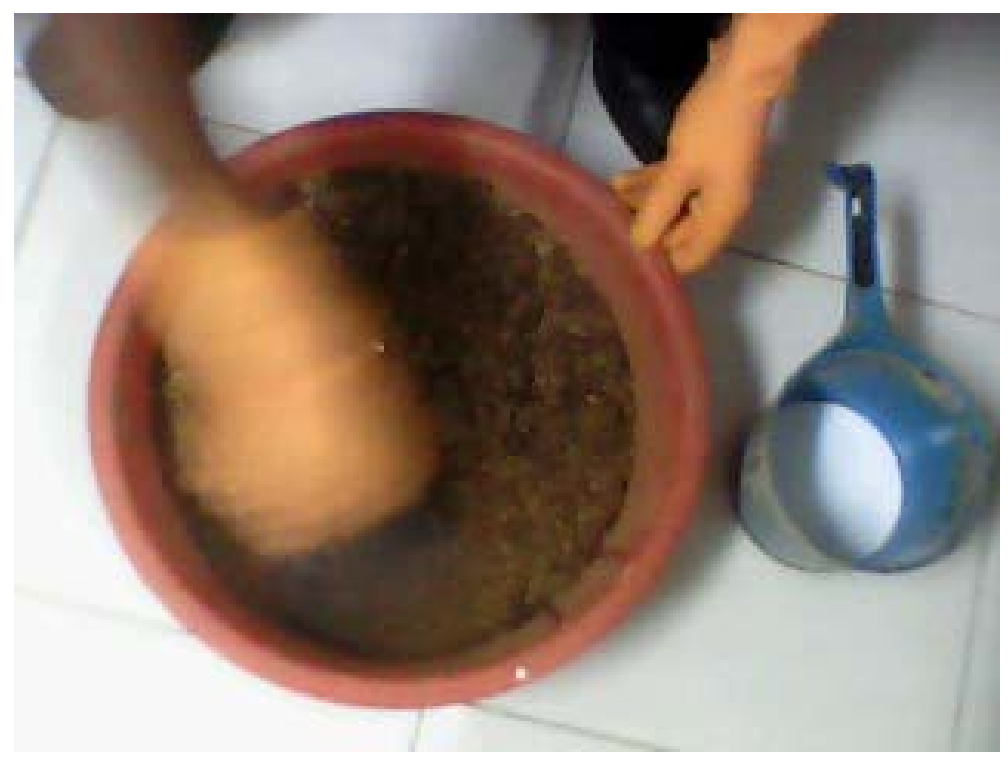

Gambar 3.1 Pencampuran Tanah dan Soil Binder.

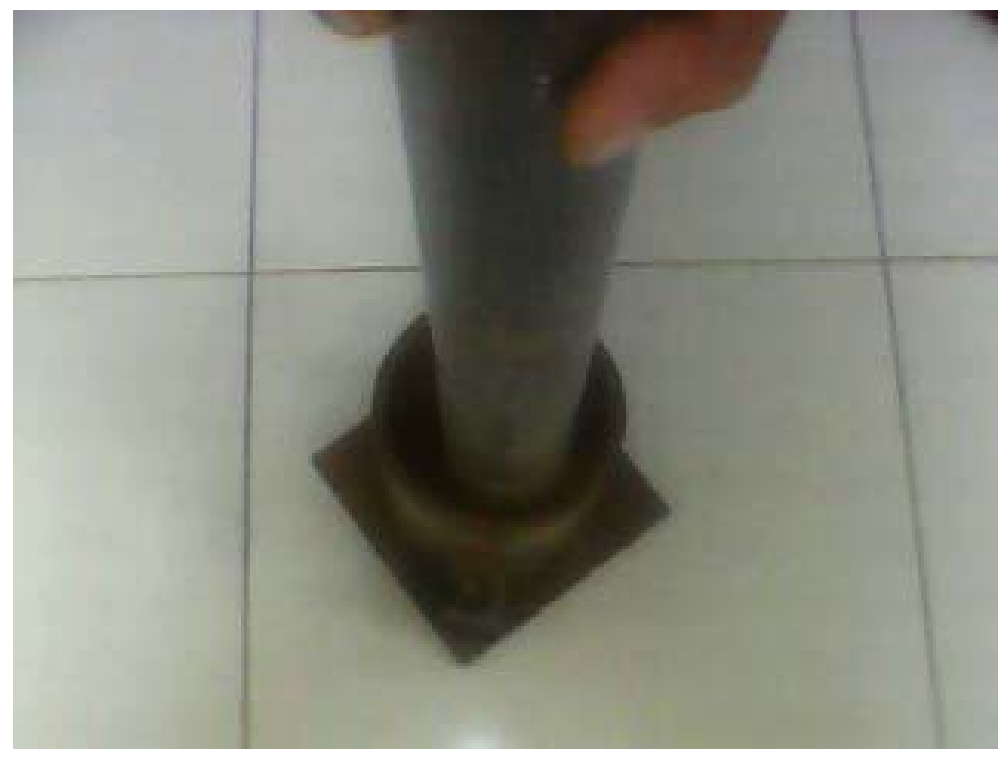

Gambar 3.2 Pemadatan campuran tanah \& Soil binder. 


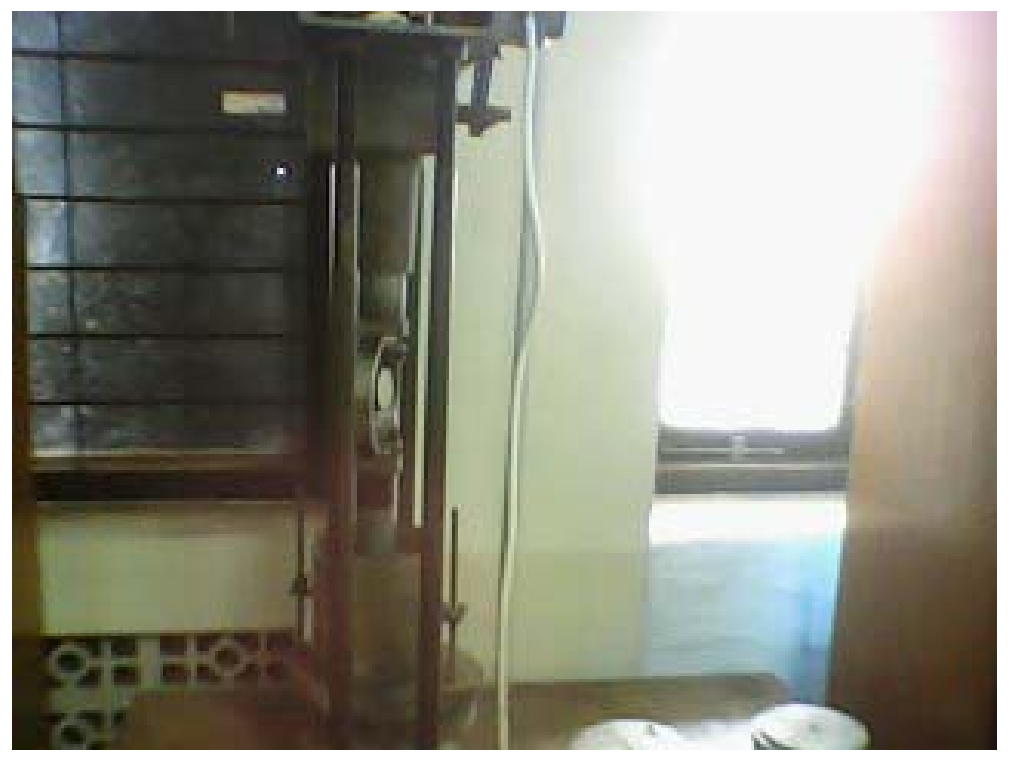

Gambar 3.3 Uji CBR.

\section{HASIL DAN PEMBAHASAN}

\subsection{Karakteristik Tanah Lempung}

Observasi secara visual di lapangan memperlihatkan warna tanah adalah coklat kemerahan. Hasil pengujian sifat fisik dan sifat mekanis tanah dapat dilihat pada tabel 4.1. Tanah memiliki Specific gravity (Gs) 2.68 yang mengindikasi tanah adalah inorganic clay.

Dari pengujian konsistensi Atterberg diperoleh nilai batas cair adalah 58.33\%, batas plastis $27.71 \%$ dan indeks plastisitas $30.62 \%$. Pengujian analisis saringan menghasilkan persentase fraksi kasar $40.90 \%$ dan fraksi halus $59.10 \%$. Berdasarkan datadata tersebut diatas dilakukan klasifikasi tanah menggunakan metoda USCS (Unified Soil Classification System). Berdasar nilai \% lolos saringan no.200 lebih besar dari 50\%, maka tanah tergolong butir halus. Dari nilai IP dan LL, terlihat pada Plasticity Chart tanah ini termasuk kategori $\mathrm{CH}$ dengan nama grup Sandy fat clay.

Sifat mekanis tanah dikaji melalui pengujian pemadatan/kompaksi dan pengujian CBR (California Bearing Ratio). Pengujian pemadatan laboratorium menggunakan standard proctor pada tanah asli (belum dicampur apapun) menghasilkan nilai kepadatan kering maksimum $\gamma_{d}=1.6 \mathrm{gr} / \mathrm{cm}^{3}$ dan kadar air optimum $22 \%$. Hasil pengujian CBR pada tanah asli dapat dilihat pada tabel 4.2. Nilai CBR design/rencana pada 95\% kepadatan kering maksimum adalah 6.9\%. Berdasar gambar 2.3 dan 2.4 nilai ini menunjukkan tanah buruk untuk dijadikan tanah dasar. 
Tabel 4.1 Hasil pengujian sifat fisik dan mekanis tanah Lampung.

\begin{tabular}{|l|l|c|c|}
\hline No. & \multicolumn{1}{|c|}{ Uraian } & Satuan & Nilai \\
\hline A & Indeks properties & & \\
\hline 1 & Specific Gravity (Gs) & - & 2.68 \\
\hline 2 & Kadar Air natural (w) & $\%$ & 35 \\
\hline B & Konsistensi Atterberg & $\%$ & 58.33 \\
\hline 1 & Batas Cair (LL) & $\%$ & 27.71 \\
\hline 2 & Batas Plastis (PL) & $\%$ & 30.62 \\
\hline 3 & Indeks Plastisitas (PI) & $\%$ & 40.90 \\
\hline C & Analisis Saringan & $\%$ & 59.10 \\
\hline 1 & Fraksi Kasar & & \\
\hline 2 & Fraksi Halus & $\mathrm{gr} / \mathrm{cm}^{3}$ & 1.6 \\
\hline D & Sifat mekanis & $\%$ & 22.00 \\
\hline 1 & $\gamma_{\mathrm{d}}$ maks (Standard Proctor) & 6.90 \\
\hline 2 & Kadar Air Optimum & & \\
\hline 3 & Daya dukung CBR & & \\
\hline
\end{tabular}

Tabel 4.2 Hasil pengujian CBR tanah asli.

\begin{tabular}{|c|c|c|c|}
\hline Tumbukan per lapis & 10 tumbukan & 25 tumbukan & 56 tumbukan \\
\hline$\gamma_{\mathrm{d}}\left(\mathrm{gr}^{\mathrm{c}} \mathrm{cm}^{3}\right)$ & 1.30 & 1.48 & 1.63 \\
\hline Nilai $\mathrm{CBR}_{0.1},(\%)$ & 2.53 & 5.75 & 8.63 \\
\hline Nilai $\mathrm{CBR}_{0.2},(\%)$ & 2.68 & 6.14 & 9.21 \\
\hline
\end{tabular}

\subsection{Pengaruh stabilisasi Soil Binder terhadap CBR Tanah Lempung}

Tabel 4.3 memperlihatkan nilai CBR tanah yang telah distabilisasi soil binder. Nilai CBR terlihat meningkat sejalan dengan peningkatan konsentrasi soil binder yang ditambahkan. Pada Tabel 4.3. terlihat nilai CBR tertinggi 19.70\% terjadi pada konsentrasi 300 gram/liter air $/ \mathrm{m}^{2}$ tanah dengan tumbukan 56 .

Tabel 4.4 memperlihatkan \% peningkatan nilai CBR untuk masing-masing konsentrasi soil binder dengan jumlah tumbukan yang berbeda-beda. Peningkatan $\gamma_{\mathrm{d}}$ berkisar antara $2-14 \%$ dan peningkatan nilai CBR berkisar antara $41-276 \%$. Peningkatan terbesar $276 \%$ dari nilai CBR tanah asli terjadi pada konsentrasi 300 gram/liter air $/ \mathrm{m}^{2}$ tanah dengan tumbukan 10 .

Stabilisasi Tanah Lempung Menggunakan Soil Binder 
Tabel 4.3 Hasil pengujian CBR tanah stabilisasi.

\begin{tabular}{|c|c|c|c|c|c|c|c|c|c|}
\hline & \multicolumn{9}{|c|}{ Konsentrasi Soil Binder yang ditambahkan } \\
\hline & \multicolumn{3}{|c|}{150 gram $/$ liter $/ \mathrm{m}^{2}$} & \multicolumn{3}{|c|}{200 gram $/$ liter $/ \mathrm{m}^{2}$} & \multicolumn{3}{|c|}{300 gram $/$ liter $/ \mathrm{m}^{2}$} \\
\hline Tumbukan & 10 & 25 & 56 & 10 & 25 & 56 & 10 & 25 & 56 \\
\hline$\gamma_{\mathrm{d}}\left(\mathrm{gr} / \mathrm{cm}^{3}\right)$ & 1.33 & 1.56 & 1.78 & 1.37 & 1.60 & 1.79 & 1.40 & 1.66 & 1.87 \\
\hline Nilai $\mathrm{CBR}_{0.1}(\%)$ & 3.58 & 8.34 & 12.51 & 5.61 & 10.45 & 14.14 & 9.45 & 14.34 & 18.46 \\
\hline Nilai $\mathrm{CBR}_{0.2},(\%)$ & 4.17 & 8.90 & 13.35 & 6.53 & 11.14 & 15.09 & 10.08 & 15.29 & 19.70 \\
\hline
\end{tabular}

Tabel 4.4 Besar peningkatan nilai CBR \& $\gamma_{\mathrm{d}}$.

\begin{tabular}{|c|c|c|c|c|c|c|c|c|c|}
\hline & \multicolumn{9}{|c|}{ Konsentrasi Soil Binder yang ditambahkan } \\
\hline & \multicolumn{3}{|c|}{150 gram $/$ liter $/ \mathrm{m}^{2}$} & \multicolumn{3}{|c|}{200 gram $/$ liter $/ \mathrm{m}^{2}$} & \multicolumn{3}{|c|}{300 gram $/$ liter $/ \mathrm{m}^{2}$} \\
\hline Tumbukan & 10 & 25 & 56 & 10 & 25 & 56 & 10 & 25 & 56 \\
\hline $\begin{array}{l}\text { Peningkatan } \gamma_{d} \\
(\%)\end{array}$ & 2.3 & 5.4 & 9.2 & 5.4 & 8.1 & 9.8 & 7.7 & 12.2 & 14.7 \\
\hline $\begin{array}{l}\text { Peningkatan } \\
\mathrm{CBR}_{0.1}(\%)\end{array}$ & 41.5 & 45.0 & 45.0 & 121.7 & 81.7 & 63.9 & 273.5 & 149.4 & 113.9 \\
\hline $\begin{array}{l}\text { Peningkatan nilai } \\
\mathrm{CBR}_{0.2},(\%)\end{array}$ & 55.6 & 45.0 & 45.0 & 143.7 & 81.4 & 63.8 & 276.1 & 149.0 & 113.9 \\
\hline
\end{tabular}

Hubungan antara berat isi kering $\gamma_{\mathrm{d}}$ dengan konsentrasi soil binder untuk jumlah tumbukan yang berbeda-beda dapat dilihat pada gambar 4.1. Secara umum harga berat isi kering $\gamma_{\mathrm{d}}$ meningkat dengan meningkatnya konsentrasi soil binder. Hubungan antara berat isi kering $\gamma_{\mathrm{d}}$ dengan konsentrasi soil binder memiliki pola yang sama pada tumbukan 10 dan 25 .

Hubungan antara nilai CBR pada penetrasi 0.1" dan 0.2" dengan konsentrasi soil binder untuk jumlah tumbukan yang berbeda-beda dapat dilihat pada gambar 4.2. dan gambar 4.3 Secara umum nilai CBR meningkat dengan meningkatnya konsentrasi soil binder. Hubungan antara nilai CBR dengan konsentrasi soil binder memiliki pola yang sama.

Nilai CBR desain pada 95\% kepadatan kering maksimum untuk tanah asli dan berbagai konsentrasi penambahan soil binder terlihat pada tabel 4.5. Peningkatan nilai CBR berkisar antara 13-76 \%. Penggunaan soil binder merk Vienison dapat dikatakan berhasil meningkatkan nilai CBR tanah dasar. Hubungan antara nilai CBR disain dengan konsentrasi dapat dilihat pada gambar 4.4. 


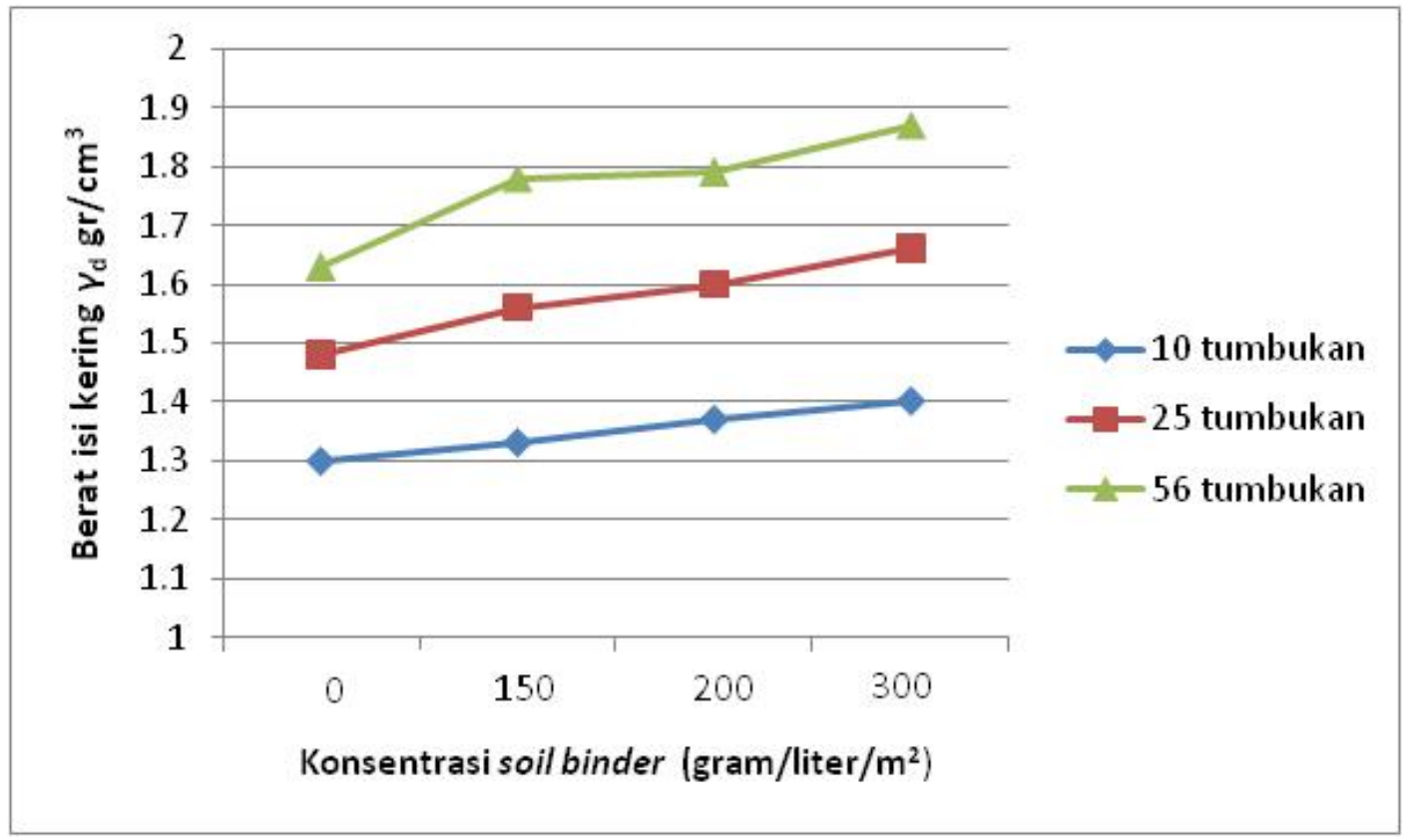

Gambar 4.1 Hubungan berat isi kering $\gamma_{d}$ dengan konsentrasi soil binder.

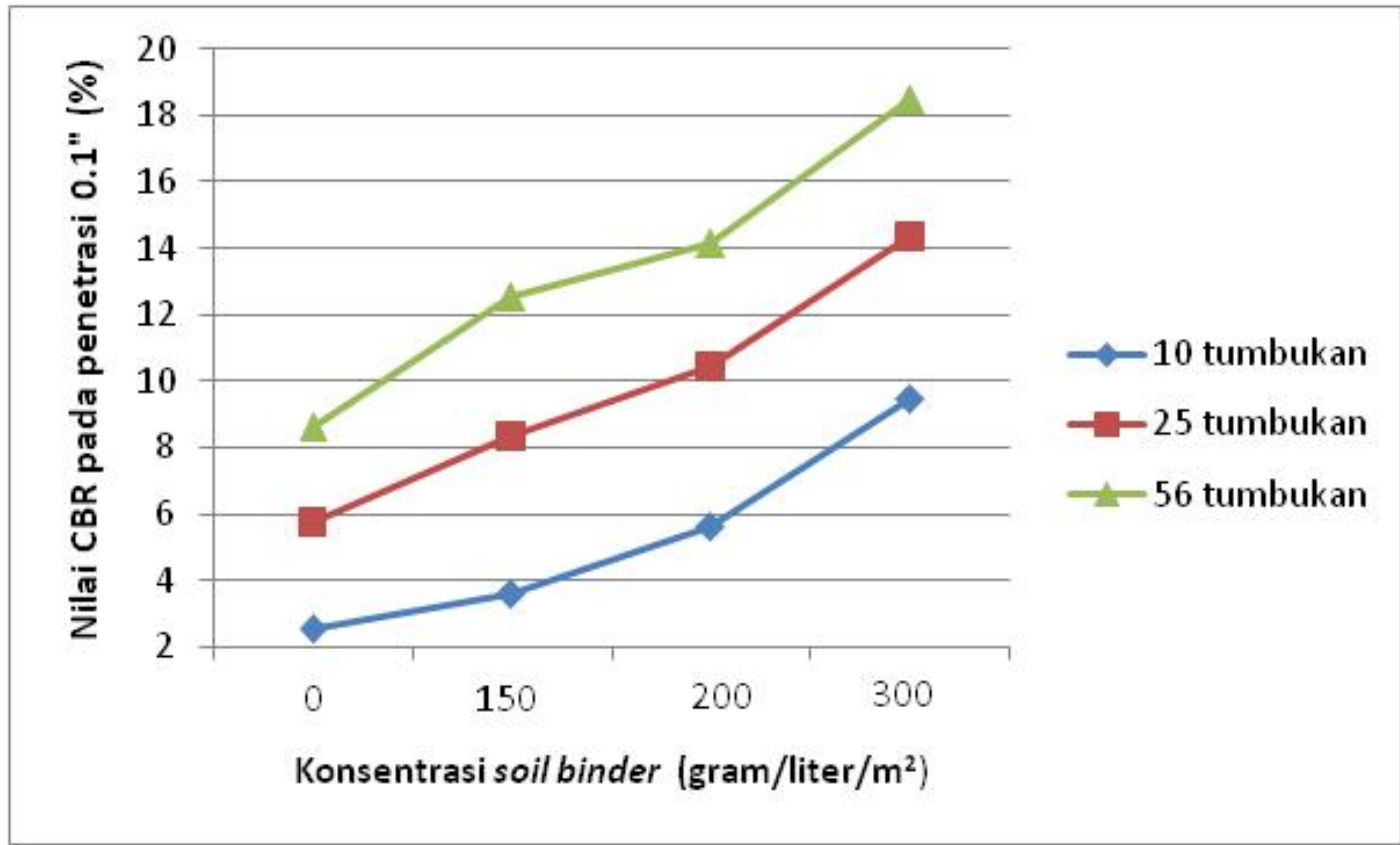

Gambar 4.2 Hubungan nilai $\mathrm{CBR}_{0.1}$ " untuk bermacam konsentrasi soil binder. 


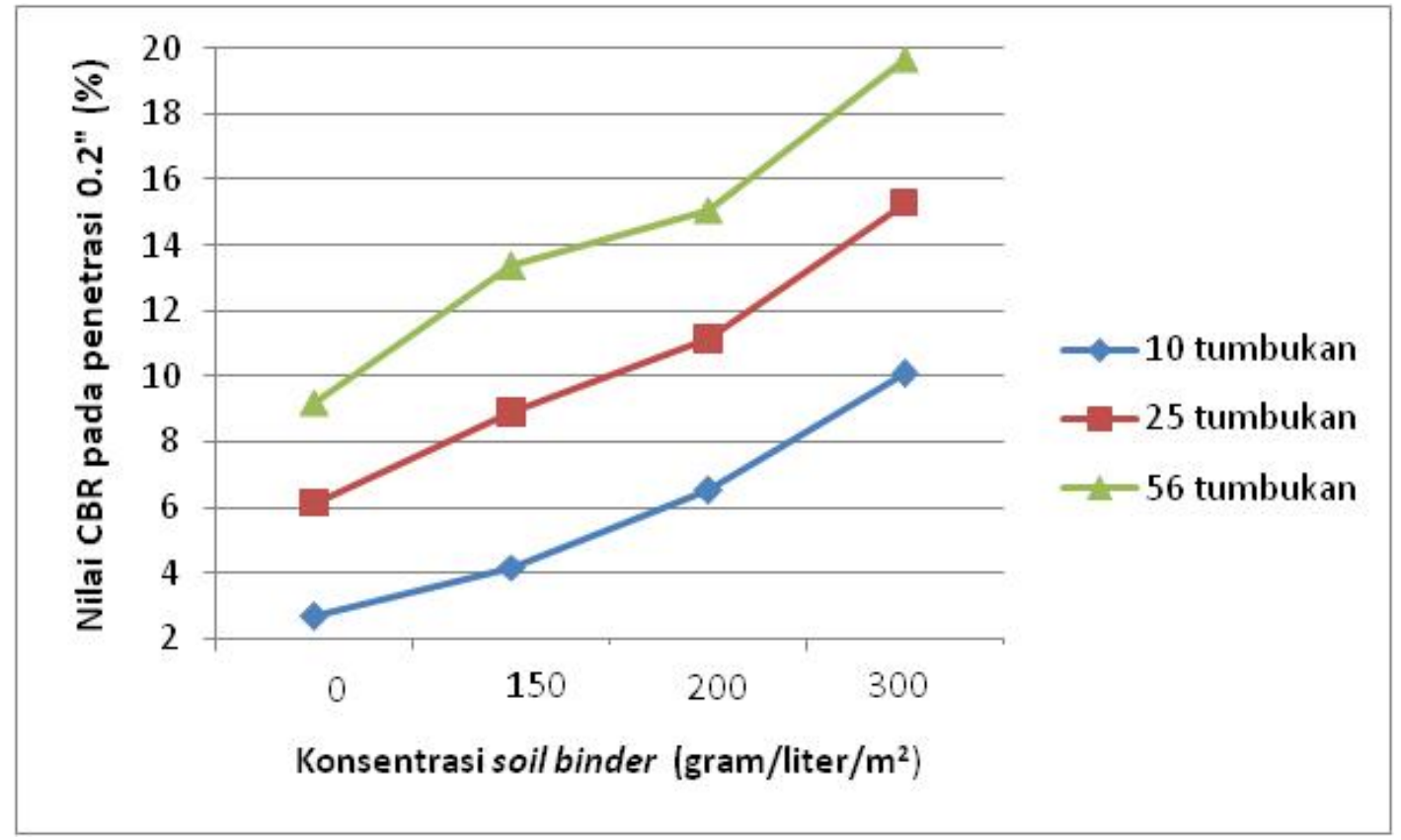

Gambar 4.3 Hubungan nilai $\mathrm{CBR}_{0.2}$ " untuk bermacam konsentrasi soil binder.

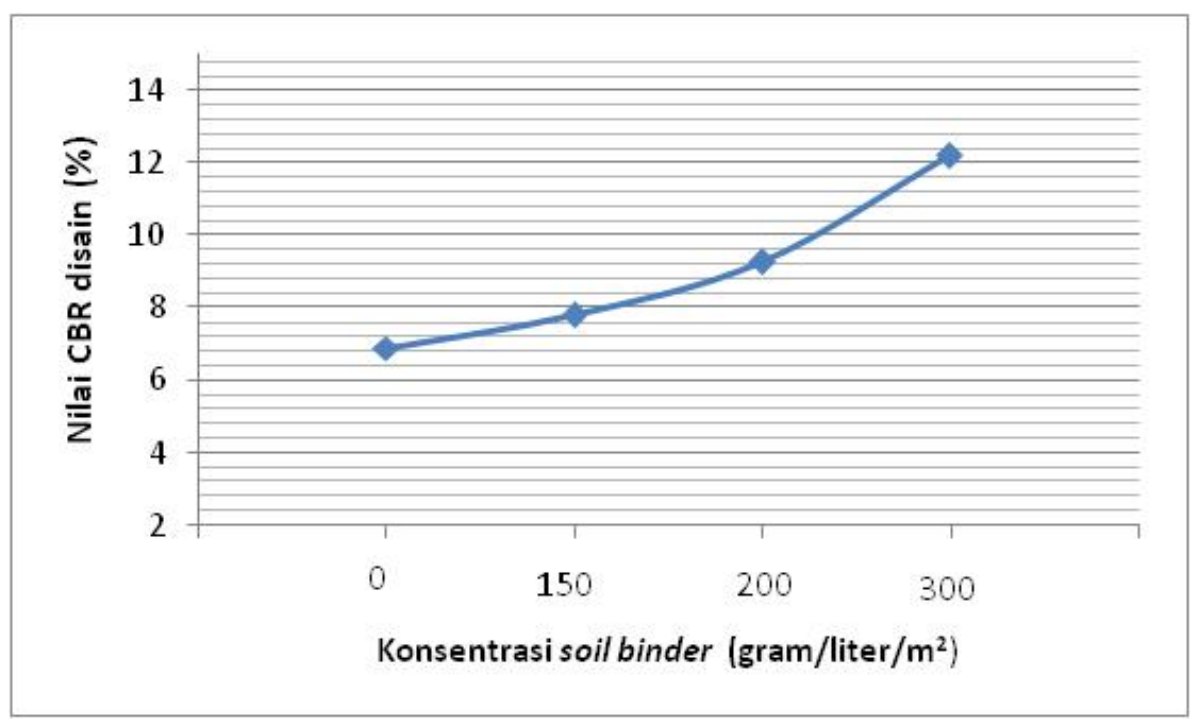

Gambar 4.4 Hubungan konsentrasi soil binder dengan nilai CBR disain.

Tabel 4.5. Nilai CBR desain.

\begin{tabular}{|l|c|c|}
\hline \multicolumn{1}{|c|}{ Material } & $\begin{array}{c}\text { CBR Design } \\
(\mathbf{\%})\end{array}$ & $\begin{array}{c}\text { Peningkatan } \\
(\mathbf{\%})\end{array}$ \\
\hline Tanah Asli & 6.90 & - \\
\hline Tanah Asli + Soil binder 150 gram/liter $/ \mathrm{m}^{2}$ & 7.80 & 13.0 \\
\hline Tanah Asli + Soil binder 200 gram/liter $/ \mathrm{m}^{2}$ & 9.25 & 34.0 \\
\hline Tanah Asli + Soil binder 300 gram/liter $/ \mathrm{m}^{2}$ & 12.20 & 76.8 \\
\hline
\end{tabular}




\section{KESIMPULAN}

\subsection{Kesimpulan}

Berdasarkan hasil pengujian dan pembahasan, maka dapat ditarik kesimpulan sebagai berikut :

1. Tanah lempung yang digunakan memiliki Gs 2.68 dan berdasar klasifikasi USCS tergolong sebagai Sandy fat clay dengan group symbol $\mathrm{CH}$.

2. Pengujian pemadatan laboratorium menggunakan standard proctor pada tanah asli menghasilkan nilai kepadatan kering maksimum $\gamma_{\mathrm{d}}=1.6 \mathrm{gr} / \mathrm{cm}^{3}$ dan kadar air optimum $22 \%$.

3. Nilai CBR desain pada $95 \%$ kepadatan kering maksimum tanah asli adalah $6.9 \%$. Nilai ini menunjukkan tanah buruk untuk dijadikan tanah dasar.

4. Akibat penambahan soil binder terjadi peningkatan $\gamma_{d}$ antara $2-14 \%$ dan peningkatan nilai CBR antara $41-276 \%$.

5. Penambahan Soil Binder sebesar 150 sampai 300 gram $/$ liter air $/ \mathrm{m}^{2}$ tanah dapat meningkatkan nilai CBR desain sebesar 13 sampai 76\%.

\subsection{Saran}

Perlu dilakukan penelitian lanjutan untuk kondisi tanah yang direndam air, agar dapat dilihat prilaku tanah stabilisasi terhadap adanya air dan sifat-sifat kerembesannya. Kandungan mineral lempung perlu diteliti lebih lanjut untuk melihat reaksi soil binder terhadap kandungan mineral apakah memperlemah atau memperkuat ikatan tanah.

\section{UCAPAN TERIMA KASIH}

Penulis berterima kasih kepada Bapak Tan dari PT Vienison Indonesia atas pemberian bahan soil binder.

\section{DAFTAR PUSTAKA}

1. Bowles, J.E., 1984, Sifat-Sifat Fisis dan Geoteknis Tanah, Penerbit Erlangga, Jakarta.

2. Chen, F.H., 1975, Foundations on Expansive Soils, Developments in Geotechnical Engineering 12, Elsevier Scientific Publishing Company, New York.

3. Cox, J.B., 1970. The Distribution and Formation of Recent Sediments in South East Asia. Proceedings Second South East Asian Conference on Soil Engineering: p.30-47. 
4. Das, Braja M., Endah, Noor. Dan Mochtar, Indrasurya B., 1988, Mekanika Tanah (Prinsip-Prinsip Rekayasa Geoteknik) Jilid 1 dan 2, Erlangga, Jakarta.

5. Holtz, R.D., and Kovacs, W.D., 1981, An Introduction to Geotechnical Engineering, Prentice Hall Inc., Englewood Cliffs, N.J.

6. Ingles, O.G., and Metcalf, J.B., 1972, Soil Stabilization, Butterworths, Sydney.

7. url: http://www.ofbcorporation.com 